\title{
ROBERTO EQUISOAIN: LA BIBLIOTECA DE LA SALA DE LECTURA SIN LECTURA, 2*
}

\section{Túa BLESA}

Universidad de Zaragoza

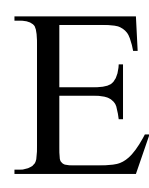

ntre las incorporaciones recientes al catálogo del ala Stéphane Mallarmé, la sala de lectura sin lectura de la Biblioteca universal, destacan, y de qué manera, varias novedades debidas a Roberto Equisoain, cuya sección tiene ya en dicha sala una importancia singular, a lo que ya presté alguna atención en (Blesa 2016). Continuando la serie de libros que de una u otra forma rehacen libros, canónicos no pocos de ellos, ya literarios, ya pertenecientes a otras series, libros renovados para hurtarlos a la lectura, rehechos en clave de ilegibilidad, serie que incluye La lectura rápida se caracteriza por el análisis de las compensaciones que se deben realizar entre la medida de velocidad y la comprensión obtenida del texto, reconociendo que los diferentes tipos de lectura resultan en diferentes niveles de lectura y tasas de comprensión, y que dichas tasas pueden ser mejoradas con la práctica, Was ist Metaphysik? de Martin Heidegger, Über den Traum /Sobre el sueño, entre otros varios volúmenes que constan ya en el fichero de dicho catálogo, llaman la atención algunos otros nuevos ${ }^{1}$.

Una de esas novedades es Caos (Equisoain 2015), cuyo título remite al antes primordial, al origen, así al menos lo dicen algunos relatos, esa conciencia que lleva por nombre el imaginario. Quien redactara el Génesis lo dejó bien claro: «La tierra era caos y confusión y oscuridad por encima del abismo» $(1,1)$ y no se trata desde luego de una lectura cuya vigencia no perdure con fuerza de verdad para algunos hasta nuestros días. Y nada diferente contaba Hesíodo en su Teogonía y lo hacía muy seguro de lo que decía, no en vano, tras su extensa petición a las Musas, debía saberse no menos inspirado que el autor genesíaco: «Ciertamente, en primer lugar, existió el Caos» (Hesíodo 1990: 45). Anterior a estos, el Poema babilónico de la Creación o Enüma eliš narra también la creación y no deja de decir que en el antes de las cosas nombradas, esto es, diferenciadas, esto es, existentes, los dioses genesíacos juntaron sus aguas, las dulces y las saladas, y de ellas, de ese caos primigenio, fueron surgiendo otros dioses y finalmente Marduk creará el universo y Ea a los humanos:

\footnotetext{
* Estas páginas están dedicadas al querido amigo José Antonio Pérez Bowie, ejemplo de compañerismo, de rigor en el trabajo, de amistad. Por lo demás, él sabe bien las razones de haber elegido las obras de las que tratan.
} 


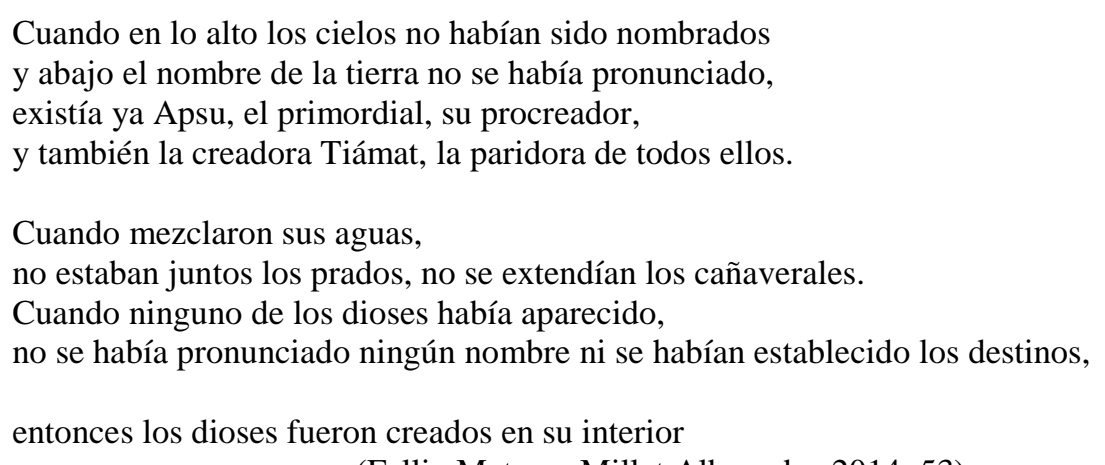

(Felliu Mateu - Millet Alba, eds., 2014: 53).

Sea, pues, el caos el origen, pero un origen en el que ya todo lo que sería creado estaba en él, que hubo de contener todas las cosas confundidas, indiferenciadas, lo que en una operación cosmética que acabaría siendo cósmica (ambas voces proceden del gr. кó $\sigma \mu \varsigma$ ) dio en el cosmos, en la totalidad ordenada, diferenciada, de las cosas. Así, en estos relatos caos y cosmos no son sino dos momentos distintos de lo mismo, un todo en cuya secuencia el cosmos se adelanta a sí mismo al (pre)existir ya en el caos. No es de extrañar, entonces, que James Joyce fundiese los dos términos en lo que acertó a nombrar en Finnegan's Wake como «chaosmos», signo que funde signos y en el que caos y cosmos, desorden y orden andan confundidos, con lo que entre ellos la indiferencia encuentra su expresión lingüística: «chaosmos».

Del éxito de la creación joyceana hablan, entre otras piezas con tal palabra en el titulo, la escultura Chaosmos de Roberto Matta, la serie de fotografías de Werner Zellien y las de Tomioka Masahiro además de sus Caosmos Machines, los trabajos de Matthieu Raffard, los objetos de Jean Bonichou, la novela de Christophe Carpentier o la canción del grupo ZIZ.

Caos, cosmos; desorden, orden; al final todo abocado a ser contado en un libro, en unos libros; caos y cosmos cabrían y confluirían en uno de ellos, lo dejó dicho Stéphane Mallarmé en «Le livre, instrument spirituel»: «tout, au monde, existe pour aboutir à un livre» (Mallarmé, 1992: 378); todo. Una ilusión del poeta que no hace sino prolongar los vínculos metafóricos entre escritura-lectura y mundo, un mundo sujeto al orden, tal como escribió Plotino al referirse al arte del adivino, que sería «leer las letras de la naturaleza, que revelan un orden y una regla» (apud Curtius, 1976: 431). Así, el Libro como mundo y el mundo como texto; Libro que, como escribiría Mallarmé en su nota autobiográfica, contendría «[1]'explication orphique de la Terre» y es de todo interés para lo que aquí importa que allí mismo se lee que el ritmo de tal Libro sería «impersonnel et vivant, jusque dans sa pagination» (Mallarmé, 1992: 663), observación esa, la de la paginación viva, que va a resultar esencial para lo que aquí importa.

Siendo que el libro, y sus antecedentes, son dispositivos que ofrecen el texto o conjunto de textos ordenado —disposición de, entre otros elementos, primeras, índice, prólogo, texto, epílogo-, todo sometido al orden de la linealidad, lo que no impide que ese orden pueda acoger cualquiera de los discursos imaginables sobre el caos y de hecho así sucede y son, si no innumerables, sí numerosos los 
discursos sobre el caos que encuentran en el libro su ordenación. Y es ahí donde interviene Roberto Equisoain y su serie de libros Caos.

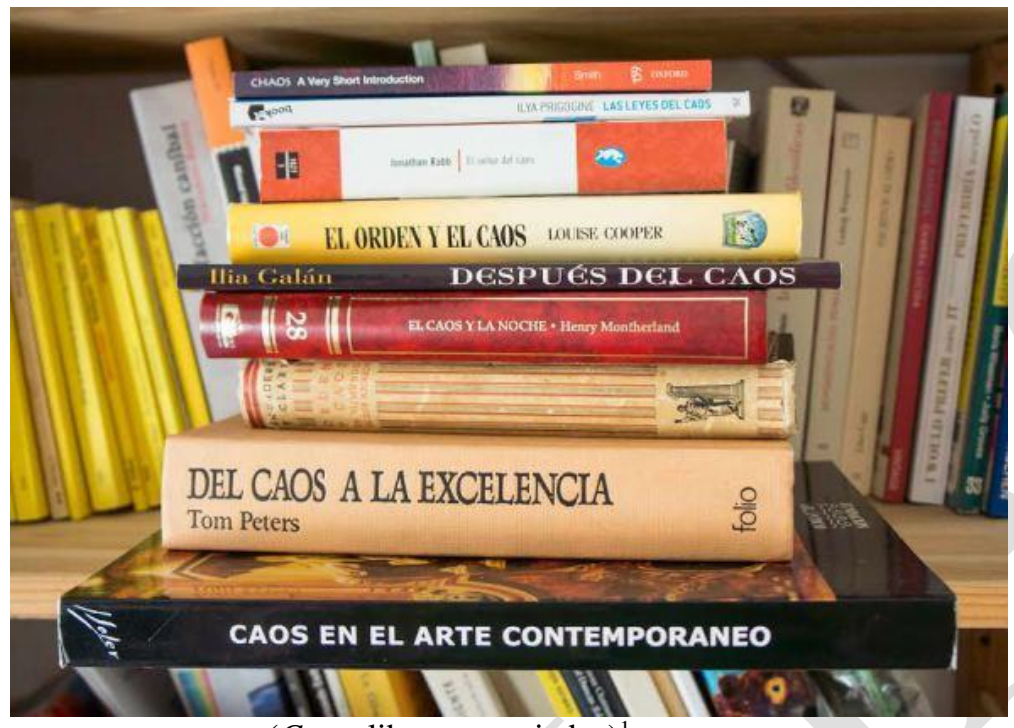

(Caos, libros apropiados) ${ }^{1}$

Surge esta serie de libros a partir de otros que han de cumplir la condición de que en el título figure la palabra «caos», sea cual sea la materia de la que traten y el interés que pudieran tener; así, libros apropiados — dichos ahí de una vez los dos significados: 'hecho algo propio de alguien' y 'ajustado y conforme a las condiciones o a las necesidades de alguien o de algo' — que, si ajenos, van a dar en libros propios; aun cuando conservan título, nombre de autor primero, etc., re-autorizados y, a su manera, reescritos y finalmente reeditados, si bien se trata de la primera edición. Equisoain, pues, selecciona, y el azar no está en ese paso del proceso abolido, sino interviniendo, libros que en el título incluyen la palabra clave: «caos» y a continuación los deshace, arranca páginas o grupos de páginas y procede a la desordenación, en lo que ha de verse la viveza del ritmo del libro, esa que Mallarmé extendía incluso a la paginación. Y una vez deshecho el orden del texto, rehace el libro en lo que ya no es más que, si fruto del desorden, otro orden. Así, los libros de la serie Caos, una vez manipulados, son libros que no sólo hablan en sus páginas del caos en este o aquel campo del saber, sino que ellos mismos son ya caóticos; libros que, en cuanto libros, pues no son ninguna otra cosa, no dejan de ser cosmos ordenados en cuanto reordenados, por lo que se puede decir que son realizaciones del caosmos. Si antes de la operación cosmética, eran libros del caos o sobre el caos, caóticos por su contenido, en su nuevo estado, lo son también su forma deshojada y rehojada, redundantes por cuanto tienen la apariencia de aquello de lo que hablan: libros caoticósmicos.

\footnotetext{
${ }^{1}$ Las imágenes están tomadas de la web del poeta-artista: https://robertoequisoain.com/, de visita muy recomendable.
} 

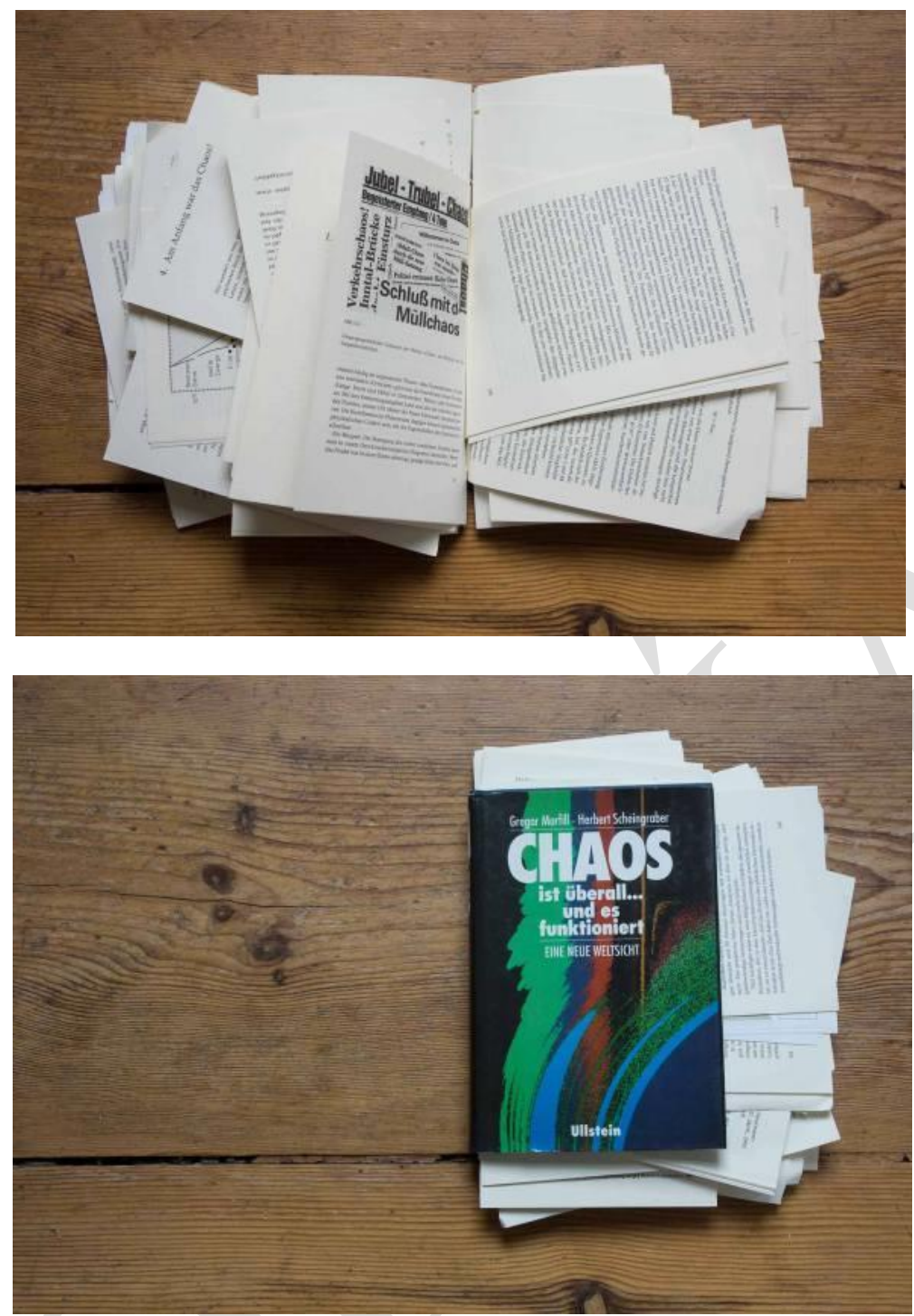

(Caos, libros propios)

Arrancadas las páginas, barajadas, recompuestos los libros, es claro que la disposición de los resultantes se aleja del orden, de la coherencia a los que los primeros autores y editores sometieron sus textos y da en una especie de tex to caótico en el que el lector avanza de salto en salto de página, avanza por un texto hecho de abruptos cortes sintácticos, de interrupciones de la significación, recorre una lectura en la que la hilación del discurso se transforma en sobresalto y quiebros de la significación, sigue, como es natural, la linealidad que es ahora quebrada, lo que hace de la lectura una escena que más recuerda a las experiencias dadaístas que a un ensayo a la usanza tradicional, camina por un texto que ha roto con las máximas que Paul Grice propuso o cualesquiera otras a las que se piense que se somete el habla y que desde luego figuran en el horizonte de expectativas del lector. Caos, lectura del sentido quebrado, lo que inscribe a esta serie de Equisoain en la tradición del nonsense, si bien en un particular modo del nonsense que, si prolonga ese tipo de discursividad, lo hace ampliándola, desplegándola: sensus interruptus podría ser un nombre para la experiencia del lector. No obstante, no se puede decir que la significación se desvanezca, sucede más bien todo lo contrario. Como escribió hace ya años N. Katheryne Hayles en La evolución del caos, y no es una opinión sino algo 
unánimemente aceptado, «[m]ientras más caótico s un sistema, más información produce. Esta percepción está en el corazón mismo de la nueva valoración del caos, porque permite que éste sea concebido como un inagotable oéano de información y no como una ausencia de significación» (Hayles, 1993: 27-28). Así, el lector de Caos habrá de ser un lector eminentemente activo, una especie de hiperhermeneuta.

Libros como La lectura rápida... — si no todo él, sí a partir de un cierto momento-, Was ist Metaphysic? —salvo en los escasísimos fragmentos que las hojas reducidas a pelotillas se ofrecen a la vista— o Über den Traum — dejando aparte lo que sea puramente conjetural—, así como la colección de los libros traducidos al blablablá (Blesa 2016), son buenas muestras de una línea de los trabajos de Equisoain que insiste en incursiones en la textualidad apropiada para asediar a la lectura al injerir en ella la ilegibilidad, dicho sea sin restricción retórica ninguna.

Si esas publicaciones hacen presente la ilegibilidad, ya total, ya parcial, en una diversidad de formas, la impenetrabilidad del texto, su cerrazón a la lectura, regresa de otro modo, aunque en último término la misma, en Textos herméticos. Se corresponde tal título con la colección de escritos catalogados como tales reunidos por Xavier Renau Nebot en 1999 en la editorial Gredos. Son, sin duda, textos herméticos, los conocidos como «Corpus hermeticum», textos de Estobeo, de Asclepio y varios otros más, que van a ir a dar también, por ese gesto de ser apropiado, en otras de las obras de Equisoain. Textos que son herméticos por Hermes, el Tot o Theut egipcio, aquel del que Sócrates le habla a Fedro:

Pues bien, oí que había en Náucratis, en Egipto, uno de los antiguos dioses del lugar al que, por cierto, está consagrado el pájaro que llaman Ibis. El nombre de aquella divinidad era el de Theuth. Fue éste quien, primero, descubrió el número y el cálculo, y, también, la geometría y la astronomía, y, además, el juego de damas y el de dados, y. sobre todo, las letras (Fedro, 274e-d),

Un Hermes-Tot que, como bien dice Xavier Renau Nebot, es «el patrón de las ciencias ocultas» (Textos herméticos: 11) y de ahí el significado de oscuros, cerrados, ocultos que se atribuye a estos escritos. Oscuridad y cerrazón del discurso que exige una lectura que ha de estar dispuesta a leer algo más, digamos que a sobreleer, lo que instituye al lector más que como intérprete como sobreintérprete. En efecto, la operación hermenéutica está ligada como con un potente pegamento a esta serie textual y por autores canónicos donde los haya. Platón en Crátilo hace decir a Sócrates que

[...] parece que Hermês tiene algo que ver con la palabra al menos en esto, en que al ser «intérprete» (hermēnea) y mensajero, así como ladrón, mentiroso y mercader, toda esta actividad gira en torno a la fuerza de la palabra. Y es que, como decíamos antes, el «hablar» (eírein) es servirse de la palabra y lo que Homero dice en muchos pasajes (eméesato «pensó», dice él) es sinónimo de «maquinar» (mēchanéesasthai). Conque, en virtud de ambas cosas, el legislador nos impuso, por así decirlo, a este dios que inventó el lenguaje y la palabra (y légein es, desde luego, sinónimo de eirein) con esta orden: «hombres, al que inventó el lenguaje y la palabra (eírein eméesato) haríais bien en llamarlo Eirémēs». Ahora, sin embargo, nosotros lo llamamos Hermês por embellecer, según imagino, su nombre (Crátilo, 407e-408b).

No podrá negarse que al personaje de Platón le falta ingenio para anudar el nombre del dios al habla y a la interpretación, y es sobresaliente la suposición cosmética del final de sus palabras, como tampoco puede negarse que lo que se dice es una sarta de barbaridades, bien que los conocimientos de 
historia de la lengua de Platón no eran los que hoy se tienen por científicos y no se le podrían exigir, lo que le exime.

Y de Platón a Martin Heidegger. Un Heidegger que escribe en un tiempo en el que ya no se puede apelar a conocimientos poco consistentes de historia de las lenguas y, sin embargo, en su «De un diálogo acerca del habla» el personaje del Inquisidor — figura que representa al propio Heidegger, al intentar explicar a su interlocutor el significado de «hermenéutico», acude a su étimo griego, el

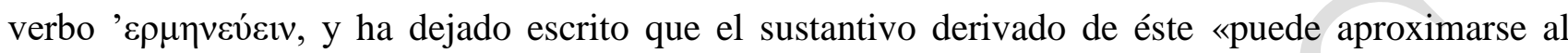
nombre del dios 'E $\rho \mu \tilde{n}_{\varsigma}$ en un juego del pensamiento que obliga más que el rigor de la ciencia» (Heidegger, 1987: 110), lo que es un argumento verdaderamente asombroso y desde luego poético. Y, en efecto, teniendo en cuenta que Hermes es, entre otras cosas, el mensajero de los dioses, la significación de hermenéutica se dirá que es, antes que el trabajo de la interpretación, el «traer mensaje y noticia», nombrado este como el sentido que sería anterior a aquel, el sentido original (111).

Con los antecedentes de Equisoain que obran en la sala de lectura sin lectura se diría que estaba escrito en las estrellas que Textos herméticos y el poeta estaban predestinados a encontrarse; en cualquier caso, así ha sido y además por partida doble. Está, por un lado, Textos herméticos a partir del tomo mencionado de Renau. Si este recoge, encierra, una serie de textos de los que conforman la tradición hermética, Textos herméticos de Equisoain también reúne, encierra esos textos, como no podría ser de otra manera si el material del nuevo libro es el otro libro, pero ahora los encierra en toda la rotundidad de la palabra. Los ejemplares de la mencionada publicación se manipulan para hacerlos en verdad herméticos. La operación es simple: se encolan los tres cortes del libro que no son el lomo, de manera que lo que resulta es un libro que no puede ser abierto, texto, ahora sí, hermético en un hermetismo que arruina cualquier intento de interpretación y deja al hermeneuta ante la pura conjetura. Ahora ya Textos herméticos no se ofrece ni siquiera a los iniciados, aquellos que todavía se podrían enfrentar a pasajes como este del Tratado 6 del Códice VI de Nag Hammadi en boca de Tat: «He recibido la vida de ti al haberme convertido en sabio. Te doy las gracias, invoco tu nombre oculto

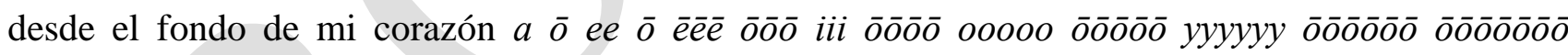
ōōōōōōōò» (Textos herméticos: 254).

Textos herméticos de Roberto Equisoain son, pues, libros no para ser leídos, lo que los hace ser extraños libros que guardan el secreto, sino para ser mirados, si bien no es algo tan extraño como para que no haya algún testimonio de curiosos lectores que no necesitan leer un libro, sino que les basta mirarlos. Es el caso, por ejemplo, de Pere Gimferrer, según escribió en L'agent provocador:

[...] a Vicente Aleixandre: més que no pas llegir-los —li deia-, sovint penso en Rimbaud, en Lautréamont; i era veritat, i encara ara, si vull, pot tornar a ser-ho: puc tornar-me a quedar mirant els lloms d'aquests dos llibres relligats en tela vermella [...] em puc quedar mirant aquests dos llibres, com aleshores, i pensar: això és Rimbaud [...] i això és Lautréamont (Gimferrer, 1998: 15, 16 y 17).

La segunda serie es Hermetismo. La selección opera ahora sobre libros que en el título presenten tal palabra. Libros escritos por quienes se sitúan en el lugar del hermeneuta y exploran textos que encerrarían sentidos no evidentes, ocultos o cuando menos oscuros y a los que se aplican variadas 
estrategias de hacerlos aflorar y en definitiva sacarlos a la luz. Equisoain, pues, una vez más se apropia de algunos de estos libros, los dota de una cubierta nueva, blanca, el color de la inocencia, del nosaber, y los encierra en tarteras translúcidas de cierre hermético que dejan leer nada más que «Hermetismo» en los contenidos, pero no dan paso a nada más, no al texto, que es, ahora sí, hermético por estar herméticamente cerrado.

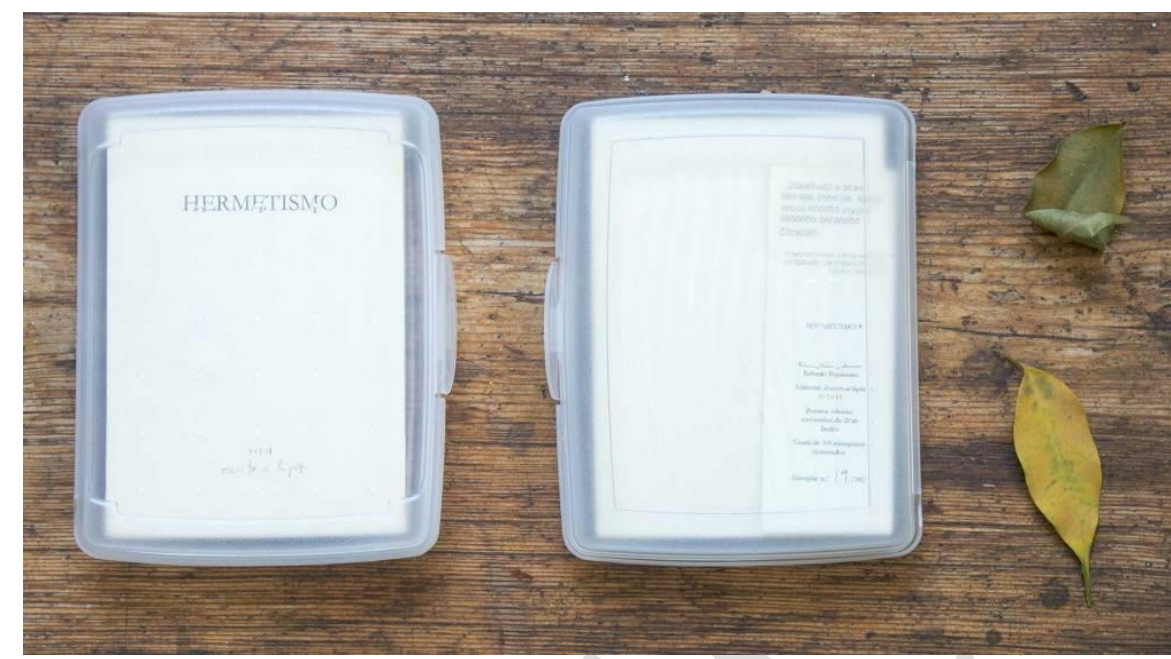

(Hermetismo)

Como el poeta, ahora cualquiera puede fijar la vista en Hermetismo de Equisoain y pensar «esto es Hermetismo», girar la mirada para focalizarla en Textos herméticos y pensar «esto es Textos herméticos». Bloqueada la lectura, unos y otros son libros para ser mirados.

En la colección de libros de Equisoain ya figura un excelente trabajo que re-presenta un texto de uno de los filósofos fundamentales del pensamiento contemporáneo, como es el ya mencionado Was ist Metaphysik? de Martin Heidegger, al que ahora se le une otra obra de otro de los filósofos no menos fundamentales, Immanuel Kant. Se trata de K4NT. Digamos ya que la alteración gráfica del título, su escritura alfanumérica, no se basa sólo en la similitud de la a mayúscula y el número 4, sino que además está indicando que son cuatro los textos de K4NT de los que Equisoain se apropia: Grundlegung zur Metaphysik der Sitten, Kritik der reinen Vernunft, Kritik der praktischen Vernunft y Kritik der Urteilskraft.

Si en el precedente heideggeriano el texto se presenta en su pura materialidad de papel al haber hecho con las hojas de la publicación un conjunto de pelotillas, con lo que las hojas no son ya tanto el soporte del discurso heideggeriano cuanto simples bolas de papel, es decir, la forma que se da al folio, a la hoja de papel antes de lanzarla a la papelera, materia, pues, con palabras, pero desde luego desechadas, bolas que no hacen sino poner ante los ojos la ilegibilidad del texto por la deformación de las hojas; si eso es así, pues, en Was ist Metaphysik?, si el texto se mantiene, no será del mismo modo en los nuevos libros que se unen a la serie filosófica. En efecto, en los libros kantianos de Equisoain el texto no está, no hay papel impreso que lo pudiera contener y su ausencia se hace presencia por medio de una metáfora. En lugar del texto, lo que contienen las cajas de $K 4 N T$ es una piedra y uno o dos sargentos que la sujetan entre sus mordazas: la inmaterialidad del discurso si se hace caso omiso 
de su realidad fónica se ve sustituida por dos cosas de cuya materialidad no cabe duda alguna: piedra y metal. Y si la metáfora se fundamenta en la semejanza, la similitudo, como anotó ya Quintiliano, no es fácil señalar a primera vista cuál pueda ser la semejanza entre el discurso filosófico y el contenido de las cajas-libro. $K 4 N T$, pues, como metáfora, pero una traslación que no es verbal, sino icónica, producto de un traslado intersemiótico. Mejor que entretenerse en especulaciones, las palabras de presentación de ellos en la web de Equisoain explican bien el concepto que sustenta el trabajo:

Unos bloques de granito u otras piedras sujetas por un sargento.

Con este ensamblaje de objetos se propone una imagen que reproduce los principios que gobiernan el proyecto filosófico de Immanuel Kant: por un lado, la realidad nouménica, cosa natural tan evidente como impenetrable. Por otro lado, un instrumentario filosófico puesto al servicio en principio de su análisis, pero que tan solo llega a sujetar o contener la cosa.

El ensamblaje propone un encuentro entre una cosa que se mantiene estable en su silencio inescrutable y hermético y el intento por medio de la creación de un fabuloso artefacto, universal, lógico y perfecto en su organización interna para acceder a ella, un artefacto que en todo caso habla más de quienes lo fabrican que de las cosas mismas que sujetan. (Equisoain, https://robertoequisoain.com/)

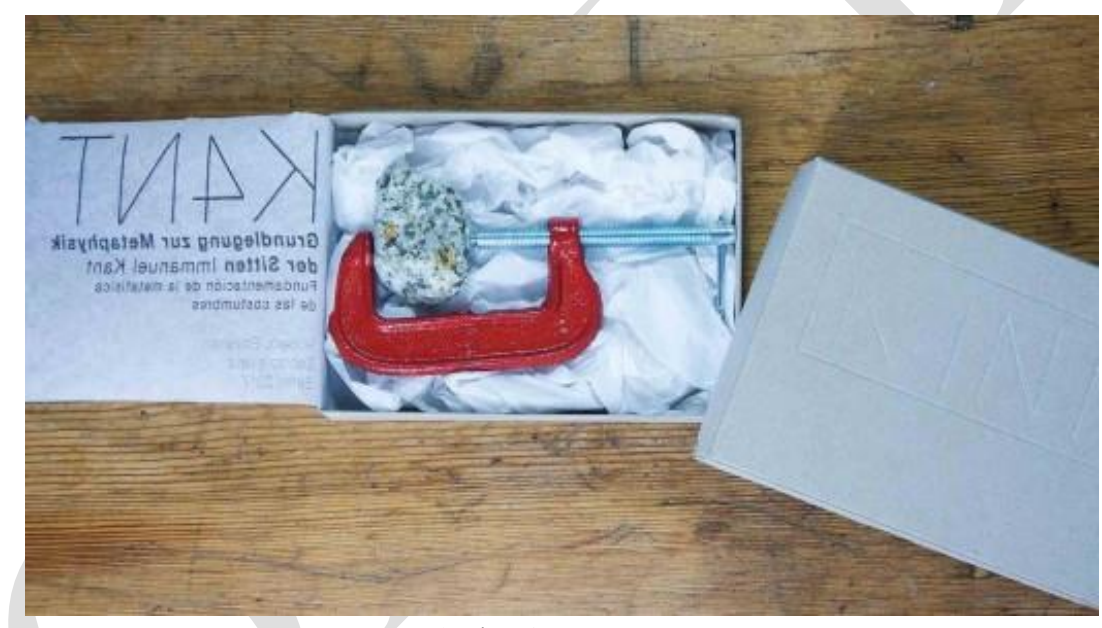

$(K 4 N T)$

Los sargentos de K4NT forman serie con otras herramientas de algunos otros de los trabajos de Equisoain. 111 lupas es una intervención en el espacio urbano en la que en la Görlitzer Bahnhof (U1) de Berlín se colocó a partir de las 11 horas 11 minutos del 11 de noviembre de 2011 una lupa — se iban reponiendo según desaparecían hasta llegar a la cantidad que el título indica— ante los azulejos de la pared como invitación a llamar la atención del transeúnte curioso — que los habría no curiosos es de suponer-, a interrumpir su caminar - hurtar algo de su tiempo, hurtarlo para que deje de ser un tiempo muerto - para hacer suya la lupa y mirar para ver ¿qué?: nada de particular, la superficie de los azulejos, los restos de celo de carteles o anuncios que allí hubo, las letras o grafismos que alguien trazó: nada de particular. Aunque ¿nada de particular? Sí en cuanto lo que con ello se daba era el irrumpir en la vida cotidiana de los otros, detener su camino, diferir su destino unos segundos, unos minutos, distraer a quien pasa por allí y hacer que mire aquello junto a lo que pasa, quizá varias veces al día y no mira nunca, hacer que vea de un modo distinto, ampliado, lo que sin haberlo mirado en 
tantas ocasiones no ha visto, un defecto en el azulejo o no, una mancha o no, un resto de algo o no, algo o simplemente la superficie del baldosín... y una lupa. Entonces ¿nada de particular? Sí, si se entiende que lo es el que lo familiar, lo ordinario, se transforme por un cierto lapso de tiempo en extraordinario. ¿Nada de particular, pues, en el gesto, el concepto, artístico de 111 lupas?

Lupas, pues, en 111 lupas. Esa misma estación de metro berlinesa fue el espacio de una nueva intervención: 33 llaves inglesas. En la misma pared, durante treinta y tres días a partir del 3 de marzo, 3 del 3, al 3 de abril de 2012 quien salía del metro se encontraba con una llave inglesa que se le ofrecía fuera del lugar que le es propio, ya no en la caja de herramientas, ya no en un taller, por ejemplo, sino allí, colgada en los baldosines de la pared de la estación de metro, lo insólito de la llave fuera de lugar atrayendo la mirada — «QQué pinta ahí una llave inglesa?»—, la llave a mano, atrayendo la mano de quien la quisiera coger. En la llave una inscripción: «internacional herrorista 33/33», la firma. Además, como en el caso de las lupas, no sujetas de un modo que fuese laborioso apropiarse de la llave, sino como en oferta.

Como en los días de 111 lupas, los de 33 llaves inglesas vuelven a irrumpir en el paso de las gentes, en sus vidas; el tránsito de todos los días sale de la rutina, es la deshabituación de lo habitual, lo que recuerda la tesis formalista del extrañamiento, enunciada hace un siglo, en los tiempos del futurismo, de las vanguardias, tesis a la que la obra de Equisoain no es en absoluto ajena. Como escribió Víktor Shklovski en 1917, el mismo año precisamente de Fountain de Marcel Duchamp, «La finalidad del arte es dar una sensación del objeto como visión y no como reconocimiento» (Shklovski, 1970: 60), tan olvidado hoy y a lo que el arte y la literatura durante cien años no han hecho sino confirmarlo. La lupa, la llave inglesa, ¿quién lo negará?, se presentan en el pasillo de la Görlitzer Bahnhof como visión.

Más herramientas: un martillo. En la instalación Frágil (2015) una caja contiene en dos espacios separados una copa Riedel y un martillo, la copa perfecta para beber vino, su cristal y el instrumento que puede fácilmente hacer presente su fragilidad. Frágil es, pues, la unión de dos objetos manufacturados, por lo que se corresponde al pie de la letra con la definición que André Breton dio en 1934 de un ready-made, una de las grandes aperturas del cosmos del arte que se deben a Marcel Duchamp: «objets manufacturés promis à la dignité d'objets d'art» (Breton, 1965: 87). Pese a que esa es la idea del ready-made generalizada, Duchamp llegó a tener otra mucho más amplia; varias décadas después de desestabilizar el arte, en 1961, diría que «como los tubos de pintura empleados por el artista son productos manufacturados y ya hechos, debemos concluir que todas las telas del mundo son readymades ayudados y trabajos de acoplamiento.» (Duchamp, 2012b: 238)

Por otra parte, a propósito de Duchamp es de recordar que entre sus lecturas preferidas estaba la obra de Mallarmé: «Mi biblioteca ideal habría contenido todos los escritos de Roussel - Brisset, tal vez Lautréamont y Mallarmé. Esa es la dirección que ha de tomar el arte: la expresión intelectual, antes que la expresión animal. Ya estoy harto de la expresión "pintamonas".» (Duchamp, 2012a: 223)

La serie de piezas con herramientas se cruza con la serie de libros nuevamente manipulados en Manifiesto comunista (2016). El libro con el célebre texto de Marx y Engels, apropiado una vez más, 
se presenta troquelado en forma no de martillo, no de hoz, que hubieran sido las figuras más esperables, sino de cabeza de hacha, a la que en algunos de los ejemplares se acompaña de un mango. Así, la trasposición icónica, un hacha: arma de caza, de guerra, de trabajo, el hacha se ofrece como imagen del llamamiento a la revolución, del discurso combativo. En el ejemplar que tengo a la vista — con la misma traducción, por cierto, que la del Manifiesto que se puede leer en la web del Partido Comunista de España (http://www.pce.es/descarga/manifiestocomunista.pdf), digamos, pues, que la versión oficial—, no se lee «hacha» (Marx y Engels, 1976)). Pese a ello, Equisoain, en una nueva traducción de lo verbal a lo icónico, es ese utensilio el que propone. Hacha: objeto que presenta ahora el libro; hacha: figuración del combate y el trabajo. Y, como es evidente, Manifiesto comunista, una vez troquelado ha perdido buena parte del texto, por tanto, texto incompleto el de Roberto Equisoain, incompleto que, pese a ello y por ello, invoca el estado de completo, lo que lo hace un caso más de logofagia (Blesa, 1998), uno más en el conjunto de la obra de este escritor que no escribe y produce libros para la sala de lectura sin lectura. Por citar una vez más a quien inauguró la biblioteca de tal sala, a Stéphane Mallarmé, digamos que la lectura ha pasado a ser, y léase en sentido absolutamente literal, «une pratique désesperée» —así en «La Musique et les Lettres»: «Strictement j’envisage la lecture comme un pratique désespérée» (Mallarmé, 1992: 647)—, práctica desesperada por cuanto la lectura no podrá ser sino fragmentaria, sin acceso posible a las partes eliminadas del texto o a todo él. Desesperación de la lectura sin lectura, que es efecto general de la logofagia.

Roberto Equisoain hace suya la singular condición de escritor sin escritura, de productor de textos sin lectura.

\section{Referencias bibliográficas}

BLeSA, Túa (1998): Logofagias. Los trazos del silencio. Zaragoza: Trópica/Anexos de Tropelías.

- (2016): «Roberto Equisoain: la biblioteca de la sala de lectura sin lectura», Actio Nova: Revista de Teoría de la Literatura y Literatura Comparada, $\mathrm{n}^{\mathrm{o}} \quad 0$ : 56-78; en http://dx.doi.org/10.15366/actionova2016.0.

BRETON, André (1965): Le surréalisme et la peinture, nueva ed. revisada y corregida, 1928-1965. París: Gallimard.

CURTIUS, Ernest Robert (1976): Literatura europea y Edad Media Latina. Trad. Margit Frank Alatorre y Antonio Alatorre. México: Fondo de Cultura Económica.

Duchamp, Marcel (2012a): «Consideraciones», en Escritos. Duchamp del signo, seguido de Notas. Ed. esp. José Jiménez. s. trad., Barcelona: Galaxia Gutenberg: 219-223.

- (2012b) «A propósito de los "Ready-mades"», en Escritos. Duchamp del signo, seguido de

Notas. Ed. esp. José Jiménez. s. trad., Barcelona: Galaxia Gutenberg: 237-238.

EQUisoAIn, Roberto (2015): Caos, Berlín, Producciones Escopeta.

— (2016a) Textos herméticos, Berlín, Escrito a lápiz.

— (2016b) Hermetismo, Berlín, Escrito a lápiz. 
— (2017a): K4NT, Berlín, Escrito a lápiz.

(2017b): https://robertoequisoain.com/

Felliu Mateu, Lluís - Millet AlBA, Adelina, eds. (2014): Enūma eliš y otros relatos babilónicos de la Creación. Barcelona, Trotta-Publicacions i Edicions de la Universitat de Barcelona.

GIMFERRER, Pere (1998): L'agent provocador. Barcelona: edicions 62.

HAYLES, N. Katherine (1993): La evolución del caos. El orden dentro del desorden en las ciencias contemporáneas. Trad. Ofelia Castilla, Barcelona: Gedisa.

HeIDEGGER, Martin (1987): «De un diálogo acerca del habla», en De camino al habla. Trad. Yves Zimmermann, Barcelona: Ediciones del Serbal.

Hesíodo (1990): Poemas Hesiódicos. Ed. María Antonia Corbera Lloveras, Madrid: Akal.

MALlARMÉ, Stéphane (1992): «La Musique et les Lettres». Oeuvres complètes. Ed. Henri Modor y G. Jean-Aubry. París: Gallimard [1945], 635-654.

MARX, Karl - ENGELs, Friedrich (1976): El manifiesto comunista. Trad. Wenceslao Roces. Madrid: Ayuso.

Platón (1992a): Crátilo, en Diálogos II, trad., intr. y nn. J. L. Calvo, Madrid, Gredos, 339-461. - (1992b): Fedro, en Diálogos III, trad., intr. y nn. Emilio Lledó Íñigo, Madrid, Gredos, 289-413.

SHKLOVSKI, Víktor (1970): «El arte como artificio». Ed. y pról. Tzvetan Todorov. Trad. Ana María Nethol. Buenos Aires: Siglo XX, 55-70.

VV. AA. (1999): Textos herméticos, intr., trad. y nn. Xavier Renau Nebot, Madrid, Gredos. 